\title{
A New Theoretical Study of Desorption Kinetics at Solid/Solution Interface by Statistical Rate Theory
}

\author{
Hadis Bas hiri \\ Department of Phy sical Chemistry, Faculty of Chemistry, University of Kashan, Kashan, 87317-51167, Iran
}

\begin{abstract}
Desorption is one of the popular methods for the design and regeneration of catalysts. For better understanding and modeling of this process, it is important to have models with theoretical basis. In the present work kinetics of solute desorption at solid/solution interface has been studied by statistical rate theory (SRT) when the system is close to equilibrium. Based on numerically generated points ( $t$; $q$ ) by the SRT equation, it has been shown that the results of numerical analysis are in good agreement with our theoretical derivation of new rate equation for desorption systems close to equilibrium. Finally the results of the present theoretical study were confirmed by analysis of two experimental systems.
\end{abstract}

Keywords Desorption Kinetics, So lid/Solution Interface, Statistical Rate Theory, Rate Equation

\section{Introduction}

Adsorption and desorption processes are the most popular methods for removal of pollutants from wastewaters [1-3]. Sometimes for contaminants separation process, adsorption method is used firstly and then to release of adsorbed species, desorption process is needed[4, 5]. Therefore desorption kinetic and equilibrium are important in understanding desorption characteristics from adsorbent.

Kinetic of desorption has been studied extensively, experimentally and theoretically. Kinetic equations commonly are used in desorption studies including zero order[6], pseudo first order[7, 8], pseudo second order[7, 8], and simple Elovich equation[9]. The mentioned models of desorption kinetics were presented experimentally and there are no theoretical interpretation for them. By applying the SRT approach, pseudo first order kinetic model has been derived for desorption at the solid/solution interface[10].

Statistical rate theory (SRT) approach has been used for modeling of desorption kinetics at gas/solid[11, 12] and solid/solution interfaces[13]. The analytical solution of the basic equation of SRT for kinetics of desorption at solid/solution interface led to a complex expression. Recently, we have derived simple equations for description of desorption kinetics at limiting conditions [10, 13].

This article is intented to derive a desorption rate equation on the basis of statistical rate theory at close to equilibrium condition.

* Corresponding author:

h.bashiri@ymail.com(Hadis Bashiri)

Published online at http://journal.sapub.org/pc

Copyright (C) 2012 Scientific \& Academic Publishing. All Rights Reserved

\section{Theory Section}

The statistical rate theory (SRT) approach, which is based on quantum mechanics and thermodynamics, has been provided by Ward[14, 15]. Rudzinski et al has shown how the SRT approach can further be generalized to describe the kinetic of adsorption at gas/solid $[16,17]$ and solid/solution $[18,19]$ interfaces. Recently, we have used the SRT approach for adsorption kinetics near the in itial times of adsorption and close to equilibrium[20] and also for description of competitive adsorption at solid/solution interface[21].

The general rate expression to describe the kinetics of adsorption is presented by the following form $[17,18]$

$$
\frac{d \theta}{d t}=K_{l s}^{\prime}\left[\exp \left(\frac{\mu_{b}-\mu_{s}}{k T}\right)-\exp \left(\frac{\mu_{s}-\mu_{b}}{k T}\right)\right]
$$

where $k$ is the Boltzmann constant and $T$ is absolute temperature, is adsorption/desorption rate at equilibrium. $\mu_{\mathrm{s}}$ and $\mu_{b}$ are the chemical potentials of the adsorbate on the surface and in the bulk phases, respectively. $\theta$ is the fractional surface coverage and is defined as $\theta=q / q_{\mathrm{m}} . q$ is the amount of adsorbate at any time and $q_{\mathrm{m}}$ is the maximum value of $q$.

The first studies to use the SRT approach to describe the sorption rate at the solid/solution interfaces were made by accepting Langmuir model of one-site-occupancy adsorption on solid surface[18]. For the Langmuirian adsorption, the chemical potential of adsorbate on the surface $\left(\mu_{\mathrm{s}}\right)$ can be expressed by[18]

$$
\mu_{s}=k T \ln \frac{\theta}{1-\theta}-k T \ln q_{s}
$$


where $q_{\mathrm{s}}$ is the molecular partition function of an adsorbed mo lecule.

In solid/solution systems, the chemical potential of adsorbate in the bulk phase $\left(\mu_{\mathrm{b}}\right)$ is given by[22]:

$$
\mu_{b}=\mu_{b}^{\circ}+k T \ln c
$$

where $c$ is concentration of solute in the bulk phase.

The following expression can be assumed for $K_{l s}^{\prime}$ [20]

$$
K_{l s}^{\prime}=K_{l s} c_{e}\left(1-\theta_{e}\right)
$$

where, $\theta_{\mathrm{e}}$ is the surface coverage at equilibrium, $c_{\mathrm{e}}$ is the equilibrium concentration of solute and $K_{\mathrm{ls}}$ is a constant.

By combination of eqs $2-4$ and eq 1 , one arrives at:

$$
\frac{d \theta}{d t}=K_{l s}{ }^{\prime}\left[K_{L} \frac{c(1-\theta)}{\theta}-\frac{1}{K_{L}} \frac{\theta}{c(1-\theta)}\right]
$$

where $K_{\mathrm{L}}$ is Langmu ir constant and is defined as

$$
K_{L}=q_{s} \exp \left(\frac{\mu_{b}^{o}}{k T}\right)
$$

Equation 5 which has been presented by Rudzinski and Plazinski, is the basic equation for description of single solute adsorption on homogeneous solid surfaces [18, 20].

The statistical rate theory (SRT) has been used by Rudzinski et al for the modeling of desorption kinetics at gas/solid interface[11, 12]. Our recent studies have concerned the description of desorption kinetics at the solid/solution interfaces by using the SRT approach[13]. It was assumed that at the start of desorption process, the bulk concentration of solute $(c)$ is equal to zero but it increases during desorption process as [13]:

$$
c=\beta\left(\theta_{i}-\theta\right)
$$

where $\beta$ is a constant and $\theta_{\mathrm{i}}$ is the fractional coverage of adsorbed molecules at the start of desorption process. By utilizing of eq 7, the basic equation of SRT for kinetics of desorption at solid/solution interface is expressed as[13]:

$$
\frac{d \theta}{d t}=K_{l s}^{\prime}\left[K_{L} \frac{\beta\left(\theta_{i}-\theta\right)(1-\theta)}{\theta}-\frac{\theta}{K_{L} \beta\left(\theta_{i}-\theta\right)(1-\theta)}\right]
$$

Recently, we have derived the following simple equation for description of desorption kinetics near the initial times of process based on the above equation[13]:

$$
\theta_{i} \ln \theta-\theta\left(1+\theta_{i}\right)+\frac{\theta^{2}}{2}=\alpha^{\prime}-k^{\prime} t
$$

where $\alpha^{\prime}$ and $k^{\prime}$ are constants.

The aim of this paper is to derive a new and simple equation from eq 8 for desorption kinetics when system is close to equilibrium. At first eq 8 is rearranged as

$$
\frac{d \theta}{d t}=\frac{K_{l s}^{\prime} K_{L} \beta}{\theta}\left(\frac{(1-\theta)^{2}\left(\theta_{i}-\theta\right)^{2}-\frac{\theta^{2}}{\left(K_{L} \beta\right)^{2}}}{(1-\theta)\left(\theta_{i}-\theta\right)}\right)
$$

$K_{\mathrm{L}}$ in the above equation can be replaced from Langmu ir isotherm $\left(K_{L}=\frac{\theta_{e}}{C_{e}\left(1-\theta_{e}\right)}\right)$. On the basis of eq 7 , the equilibrium bulk concentration $\left(c_{\mathrm{e}}\right)$ in Langmu ir isotherm is equal to $\beta\left(\theta_{i}-\theta_{e}\right)$, so

$$
\frac{d \theta}{d t}=\frac{K_{l s}^{\prime} K_{L} \beta}{\theta}\left(\frac{(1-\theta)^{2}\left(\theta_{i}-\theta\right)^{2}-\frac{\theta^{2}\left(\theta_{i}-\theta_{e}\right)^{2}\left(1-\theta_{e}\right)^{2}}{\left(\theta_{e}\right)^{2}}}{(1-\theta)\left(\theta_{i}-\theta\right)}\right) \text { (11) }
$$

By rearrangement of eq 11 , one arrives at

$$
\frac{d \theta}{d t}=\frac{K_{l s}^{\prime} K_{L} \beta}{\theta \theta_{e}^{2}}\left(\theta_{e}-\theta\right)\left(\theta_{i}-\theta \theta_{e}\right)\left(\frac{\left[\left(\theta_{e}+\theta\right)\left(\theta_{i}+\theta \theta_{e}\right)\right]-2 \theta \theta_{e}\left(1+\theta_{i}\right)}{(1-\theta)\left(\theta_{i}-\theta\right)}\right)
$$

and since the system is close to equilibrium, the assumptions of $\theta_{e}+\theta \approx 2 \theta_{e}, \frac{1-\theta_{e}}{1-\theta} \approx 1$ and $\frac{\theta_{i}-\theta_{e}}{\theta_{i}-\theta} \approx 1$ in eq 12 are acceptable. Based on these assumptions eq 12 simplifies to

$$
\frac{d \theta}{d t}=\frac{2 K_{l s}^{\prime} K_{L} \beta}{\theta_{e}^{2}}\left(\theta_{e}-\theta\right)\left(\theta_{i}-\theta \theta_{e}\right)
$$

By using Lang muir isotherm and eq 4 , one arrives at

$$
\frac{d \theta}{d t} \frac{2 K_{l s} \beta}{\theta_{e}}\left(\theta_{e}-\theta\right)\left(\theta_{i}-\theta \theta_{e}\right)
$$

Based on the present derivation, the integration of the mentioned kinetic model should be done with the boundary condition $\theta\left(t_{1}\right)=\theta_{1}$. Where, $\mathrm{t} 1$ is the time after which eq 14 can be used. Therefore integration of eq 14 with the boundary condition $\theta\left(t_{1}\right)=\theta_{1}$ yields

$$
\ln \frac{\theta_{i}-\theta \theta_{e}}{\theta_{e}-\theta}=\alpha+K t
$$

where $K$ and $\alpha$ are constant and are equal to

$$
\begin{aligned}
K & \equiv \frac{2 K_{l s} \beta}{\theta_{e}}\left(\theta_{i}-\theta_{e}^{2}\right) \\
\alpha & \equiv \ln \frac{\theta_{i}-\theta_{1} \theta_{e}}{\theta_{e}-\theta_{1}}-K t_{1}
\end{aligned}
$$

As shown in eq 15, it is expected that the plot of $\ln \frac{\theta_{i}-\theta \theta_{e}}{\theta_{e}-\theta}$ is a linear function of time (for $t \geq t_{1}$ ). The intercept of this plot is $\alpha$ and the tangent is $K$. In the next section by using generated and experimental data the accuracy of present derivations will be discussed.

\section{Results and Discussion}

In this section, we are going to analyse the applicability of the derived equation (eq 15). The analytical solution of eq 8 led to a complex expression. One powerful technique for numerical simulations is stochastic simulation. For this purpose three sets of hypothetical kinetic data points ( $q$; $t$ ) were generated based on SRT rate equation for desorption at solid/solution interface (eq 8). For this purpose we applied the CKS package developed by Houle and Hinsberg[23,24]. Recently we utilized this method for numerical solution of some adsorption and desorption kinetic equations, success fully $[10,13,20]$.

For simplification of eq 8 the adsorption and desorption rate constants $\left(k_{\mathrm{a}}\right.$ and $k_{\mathrm{d}}$ ) are defined as 


$$
\begin{gathered}
k_{a}=K_{l s}^{\prime} K_{L} \\
k_{d}=\frac{K_{l s}^{\prime}}{K_{L}}
\end{gathered}
$$

Combination of eq 8 and above equations gives

$$
\frac{d \theta}{d t}=k_{a} \frac{\beta\left(\theta_{i}-\theta\right)(1-\theta)}{\theta}-k_{d} \frac{\theta}{\beta\left(\theta_{i}-\theta\right)(1-\theta)}
$$

The generated data were obtained by considering certain values of $q_{\mathrm{i}}$ (the a mount of adsorbate on the surface at the start of desorption), $q_{\mathrm{m}}, k_{\mathrm{a}}$ and $k_{\mathrm{d}}$ (Table 1 and 2)[13]. Three sets of desorption kinetic data points $(q ; t)$ with similar initial condition (Table 1 and 2) but different $k_{\mathrm{d}}$ values (Table 2) were generated. The different values of $k_{\mathrm{d}}$ were used to make different values of Langmuir equilibrium constant $\left(K_{\mathrm{L}}\right)$.

Table 1. The constants which have been used for desorption kinetic modeling

\begin{tabular}{|c|c|c|c|c|}
\hline system & $q_{i}(\mathrm{mg} / \mathrm{g})$ & $q_{m}(\mathrm{mg} / \mathrm{g})$ & $\begin{array}{c}M_{w} \\
(\mathrm{~g} / \mathrm{mol})\end{array}$ & $\begin{array}{c}c_{\text {adsorbent }} \\
(\mathrm{g} / \mathrm{L})\end{array}$ \\
\hline $\begin{array}{c}\text { SRT }(\text { generated } \\
\text { data) }\end{array}$ & 60.00 & 60.00 & 60.00 & 10.00 \\
\hline $\begin{array}{c}\text { Vitamin E } / \\
\text { silica }\end{array}$ & $53.86 \times 10^{-1}$ & $36.21 \times 10^{-3}$ & $43.07 \times 10^{1}$ & 20.00 \\
\hline $\begin{array}{c}\text { Cd(II)/ } \\
\text { Aeromonas } \\
\text { caviae }\end{array}$ & 37.64 & $15.53 \times 10^{1}$ & $11.20 \times 10^{1}$ & $10.00 \times 10^{-1}$ \\
\hline
\end{tabular}

Table 2. The values of $k_{\mathrm{a}}$ and $k_{\mathrm{d}}$ used for different systems, the adjustable

\begin{tabular}{|c|c|c|c|c|c|}
\hline \multirow[b]{2}{*}{ system } & \multirow{2}{*}{$\begin{array}{c}k_{a} \\
\left(\min ^{-1}\right)\end{array}$} & \multirow{2}{*}{$\begin{array}{c}k_{d} \\
\left(\mathrm{~mol}^{2} / \mathrm{L}^{2}\right. \\
\min )\end{array}$} & \multirow[b]{2}{*}{$\theta_{e}$} & \multicolumn{2}{|c|}{$K_{l s}$} \\
\hline & & & & SRT & $\mathrm{Eq} 15$ \\
\hline $\begin{array}{l}\text { Generate } \\
\text { d data } 1\end{array}$ & $1.00 \times 10^{-5}$ & $1.00 \times 10^{-5}$ & $1.64 \times 10^{-2}$ & $0.61 \times 10^{-1}$ & $0.62 \times 10^{-1}$ \\
\hline $\begin{array}{l}\text { Generate } \\
\text { d data } 2\end{array}$ & $1.00 \times 10^{-5}$ & $1.00 \times 10^{-4}$ & $6.00 \times 10^{-3}$ & 0.17 & 0.16 \\
\hline $\begin{array}{l}\text { Generate } \\
\text { d data } 3\end{array}$ & $1.00 \times 10^{-5}$ & $1.00 \times 10^{-6}$ & $4.97 \times 10^{-2}$ & $0.20 \times 10^{-1}$ & $0.24 \times 10^{-1}$ \\
\hline $\begin{array}{l}\text { Vitamin } \\
\text { E / silica }\end{array}$ & $1.00 \times 10^{-3}$ & $1.00 \times 10^{-13}$ & $2.36 \times 10^{-2}$ & $0.24 \times 10^{5}$ & $0.22 \times 10^{5}$ \\
\hline $\begin{array}{c}\mathrm{Cd}(\mathrm{II}) / \\
\text { Aeromon } \\
\text { as caviae }\end{array}$ & $2.80 \times 10^{-3}$ & $2.15 \times 10^{-9}$ & $1.56 \times 10^{-1}$ & $0.14 \times 10^{2}$ & $0.13 \times 10^{2}$ \\
\hline
\end{tabular}
values of $\theta_{\mathrm{e}}$ and the $K_{\mathrm{ls}}$ values obtained for different systems based on different kinetic models

In the first system, $k_{\mathrm{a}}$ is equal to $k_{\mathrm{d}}\left(k_{\mathrm{a}}=1.00 \times 10^{-5} \mathrm{~min}^{-1}\right.$, $\left.k_{\mathrm{d}}=1.00 \times 10^{-5} \mathrm{~mol}^{2} / \mathrm{L}^{2} \cdot \mathrm{min}\right)$. The generated data $(q ; t)$ based on SRT equation (eq 20), are shown in Figure 1(a). With utilization of generated data, values of $\ln \frac{\theta_{i}-\theta \theta_{e}}{\theta_{e}-\theta}$ as a function of time were calculated for close to equilibrium data (see eq 15) and plotted in Figure 1(b). The value of $\theta_{\mathrm{e}}$ was adjusted until the intercept of the linear plot became equal to $\alpha$ (eq 17). The adjustable value of $\theta_{\mathrm{e}}$ is reported in Table 2. By utilizing the slope of Figure 1(b) ( $K$ constant), the value of $K_{\mathrm{ls}}$ was calculated by eq 16 and was reported in Table 2 . The $K_{\text {ls }}$ value was obtained from the SRT rate equation by eqs 4,18 and 20 and is reported in Table 2 . Agreement between the obtained $K_{\mathrm{ls}}$ values from the SRT rate equation and from eq 15 , confirms the accuracy of new derived equation.
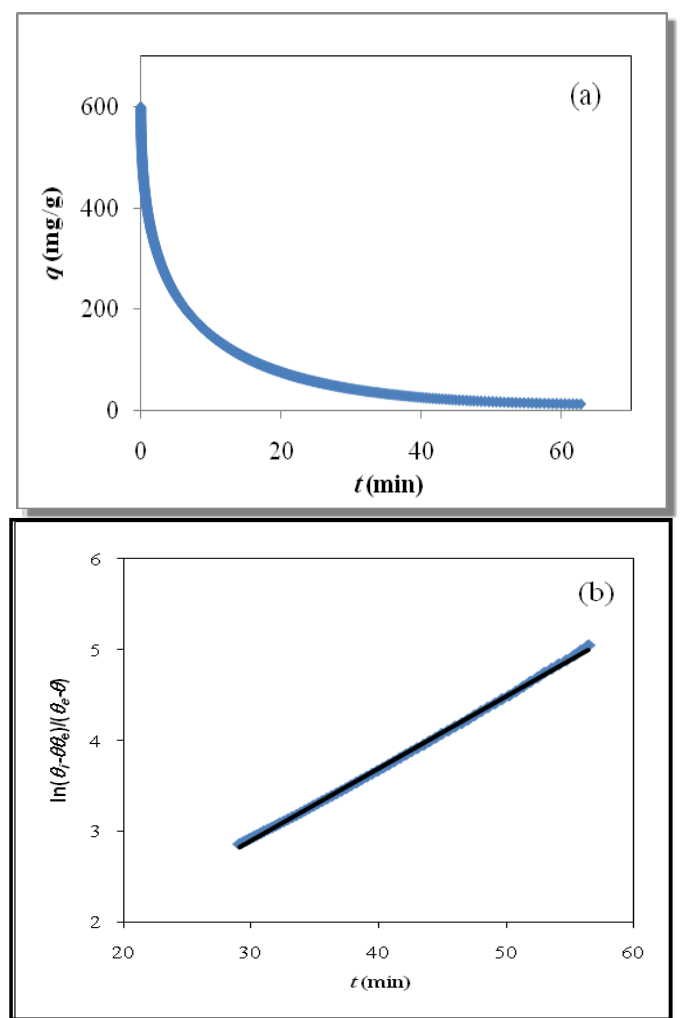

Figure 1. (a) Numerically generated data points $(t ; q)$ based on SRT equation for $k_{\mathrm{a}}=1.00 \times 10^{-5} \mathrm{~min}^{-1}$ and $k_{\mathrm{d}}=1.00 \times 10^{-5} \mathrm{~mol}^{2} / \mathrm{L}^{2}$. min. (b) Linear plot of eq 15 when system is close to equilibrium

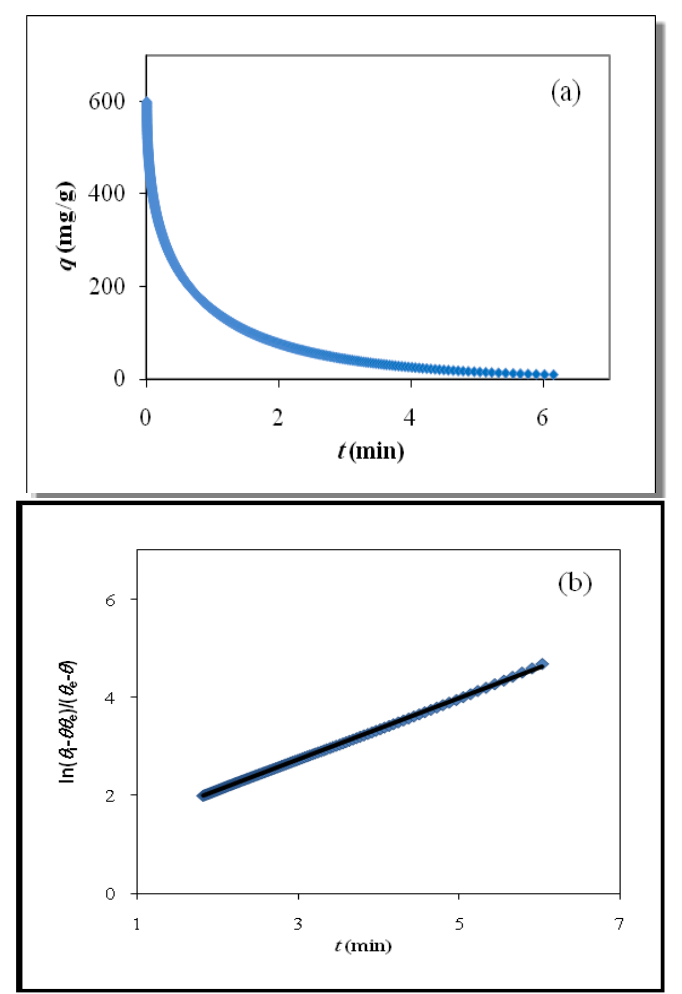

Figure 2. (a) Numerically generated data points $(t ; q)$ based on SRT equation for $k_{\mathrm{a}}=1.00 \times 10^{-5} \mathrm{~min}^{-1}$ and $k_{\mathrm{d}}=1.00 \times 10^{4} \mathrm{~mol}^{2} / \mathrm{L}^{2} . \mathrm{min}$, (b) Linear plot of eq 15 when system is close to equilibrium 
Two other sets of kinetic data points were generated by $k_{\mathrm{a}}<k_{\mathrm{d}}\left(k_{\mathrm{a}}=1.00 \times 10^{-5} \mathrm{~min}^{-1}, k_{\mathrm{d}}=1.00 \times 10^{-4} \mathrm{~mol}^{2} / \mathrm{L}^{2} \cdot \mathrm{min}\right)$ and $k_{\mathrm{a}}>k_{\mathrm{d}}\left(k_{\mathrm{a}}=1.00 \times 10^{-5} \mathrm{~min}^{-1}, k_{\mathrm{d}}=1.00 \times 10^{-6} \mathrm{~mol}^{2} / \mathrm{L}^{2} . \mathrm{min}\right)$. The generated data points $(q ; t)$ of these two systems are shown in Figure 2(a) and Figure 3(a). The values of $\theta_{\mathrm{e}}$ and $K$ were obtained by plotting of $\ln \frac{\theta_{i}-\theta \theta_{e}}{\theta_{e}-\theta}$ vs time for close to equilibrium desorption kinetic data (Figure 2(b) and Figure 3(b)). The values of $\theta_{\mathrm{e}}$ were obtained as adjustable parameters and are listed in Table 2. The $K_{\text {ls }}$ values calculated from these results are listed in Table 2 . The comparison between the obtained $K_{\mathrm{ls}}$ values and the original ones (calculated by SRT rate equation) proves the accuracy of the above derivation again.

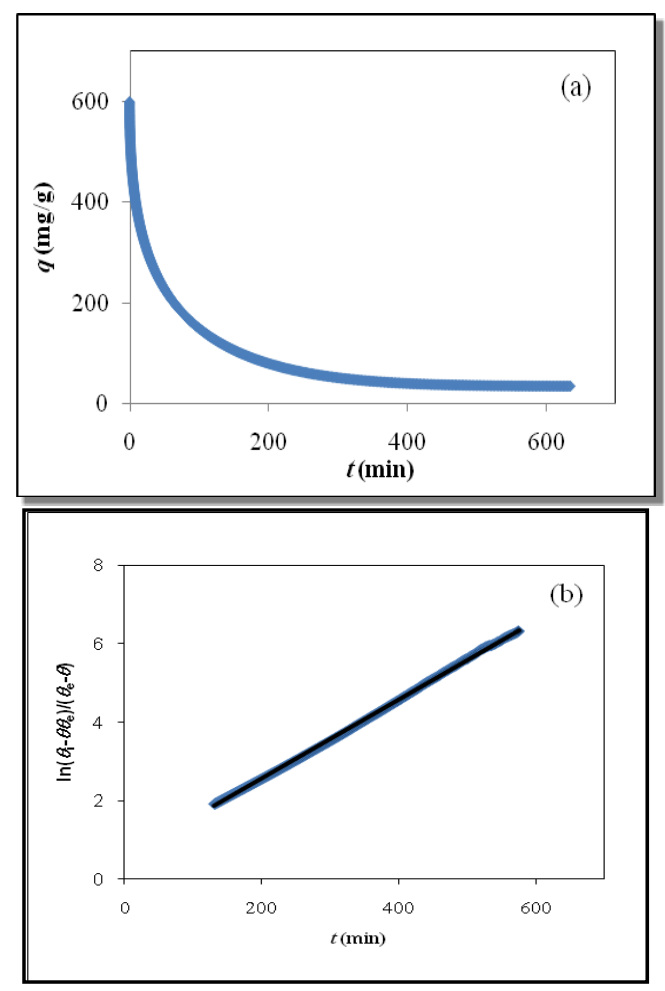

Figure 3. (a) Numerically generated points $(t ; q)$ based on SRT equation for $k_{\mathrm{a}}=1.00 \times 10^{-5} \mathrm{~min}^{-1}$ and $k_{\mathrm{d}}=1.00 \times 10^{-6} \mathrm{~mol}^{2} / \mathrm{L}^{2} \cdot \mathrm{min}$, (b) linear plot of eq 15 when the system is close to equilibrium

In this section two different sets of experimental data have been selected from the literatures[25, 26] to be analysed by SRT approach. The first experimental system that was considered is from the paper of Quek et al[25], which reports batch desorption study of vitamin $\mathrm{E}$ from silica. The experimental kinetic data at $40^{\circ} \mathrm{C}$ were fitted to the SRT rate equation (eq 20) by the stochastic numerical simulation method. The input data for simulation are written in Table 1 . The values of $k_{\mathrm{a}}$ and $k_{\mathrm{d}}$ were adjusted until a reasonable fit to the experimental kinetic data was obtained. The obtained values of $k_{\mathrm{a}}$ and $k_{\mathrm{d}}$ are reported in Table 2. The experimental and simulated values of $q$ as a function of time are represented in Figure 4(a). The values of $\ln \frac{\theta_{i}-\theta \theta_{e}}{\theta_{e}-\theta}$ as a function of time were plotted for desorption kinetic data close to equilibrium (Figure 4(b)), the $K_{\mathrm{ls}}$ and $\theta_{\mathrm{e}}$ values were obtained and are listed in Table 2 . The obtained values of $K_{l s}$ are close to the original ones $\left(K_{\mathrm{ls}}\right.$ obtained from SRT rate equation). The obtained results of these experimental data prove the accuracy of our derivation for desorption rate equation.

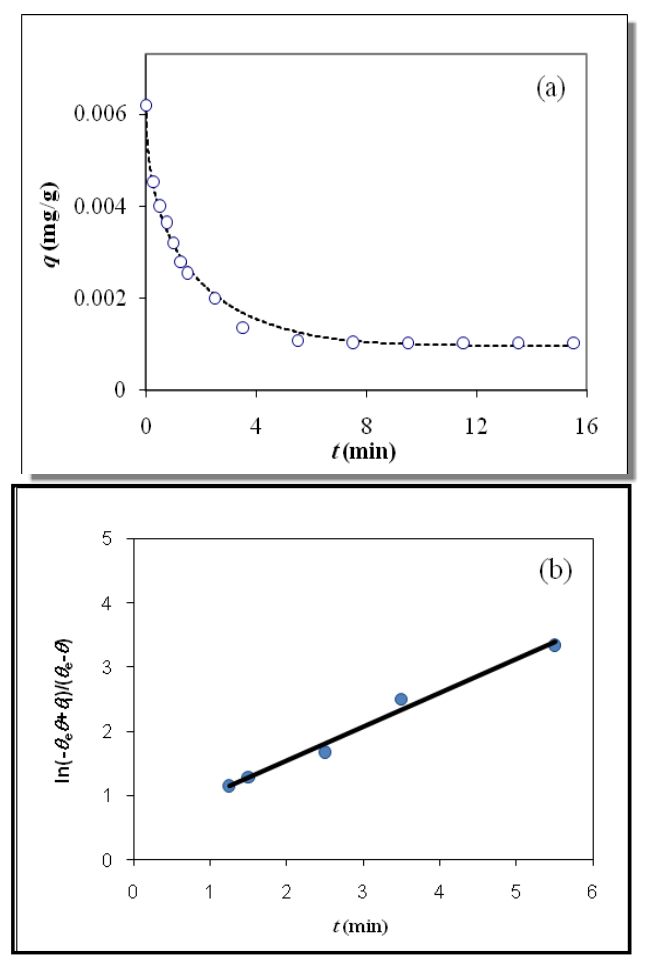

Figure 4. (a) Desorption kinetics of vitamin E from silica, experimental data (open circles) ${ }^{25}$ and theoret ical data based on SRT equation (solid line), (b) Linear plot of eq 15 when the system is close to equilibrium

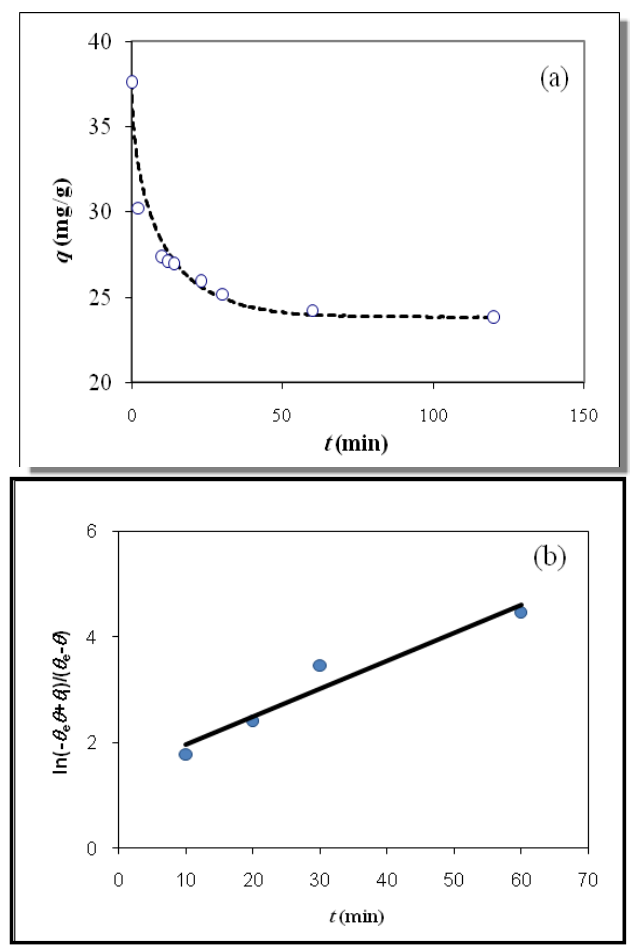

Figure 5. (a) Desorption kinet ics of Cadmium(II) from Aeromonas caviae, experimental data (open circles) ${ }^{26}$ and theoretical data based on SRT equation (solid line), (b) Linear plot of eq 15 when the system is close to equilibrium 
The next experimental desorption system that has been selected to be analysed is desorption of Cadmium(II) from Aeromonas caviae[26]. The results of fitting of experimental data by SRT desorption rate equation is shown in Figure 5(a). The values of $k_{\mathrm{a}}$ and $k_{\mathrm{d}}$ are obtained as adjustable parameters and are listed in Table 2. Utilizing eq 16 for close to equilibrium kinetic data of this system (Figure 5(b)) gives acceptable values of $K_{\mathrm{ls}}$ (Table 2).

\section{Conclusions}

The desorption kinetics at the solid/solution interfaces has been studied based on SRT approach at close to equilibrium condition. By considering some assumptions on SRT rate equation, a new rate equation was derived for desorption at solid/solution interface when system is close to equilibrium.

Three different sets of nu merical desorption kinetic data ( $q$; $t$ ) were generated by using SRT rate equation. By utilizing these generated data, the accuracy of the new derived rate equation (eq 15) has been proved. On the basis of two experimental kinetic data, it was indicated that eq 15 can be used for modeling of desorption kinetic data when system is close to equilibrium. Both experimental and generated data were in good agreement with our derivation.

For modeling of desorption kinetics based on SRT approach, but by simple equations, one have to use eq 9 for initial times of desorption and eq 15 for near to equilibrium conditions.

\section{REFERENCES}

[1] Y. Yin, H.E. Allen, C.P. Huang, D.L. Sparks and P.F. Sanders, "Kinetics of mercury(II) adsorption and desorption on soil", ACS, Environ. Sci. Technol., vol. 31, pp. 496 -503, 1997.

[2] Y.S. HO and G. McKay, "Batch lead(II) removal from aqueous solution by peat: Equilibrium and Kinetics", Institution of Chemical En gin eers, Trans. IchemE Part B, vol. 77, pp. 165-173, 1999.

[3] Z. Reddad, C. Gerente, Y. Andres and P.L. Cloirec, "Adsorption of several metal ions onto a low-cost biosorbent: kinetic and equilibrium studies", ACS, Environ. Sci. Technol., vol. 36, pp. 2067-2073, 2002.

[4] D. Chatzopoulos, A. Varma and R.L Irvine, "Activated carbon adsorntion and desorption of toluene in the aqueous phase", Wiley, AIChE J., vol. 39, pp. 2027-2041, 1993.

[5] A. Karimi-Jashni and R.M. Narbaitz. "Impact of $\mathrm{pH}$ on the adsorption and desorption kinetics of 2-nitrophenol on activated carbons", Elsevier, Water Res., vol. 31, pp. 3039-3044, 1997.

[6] A. Reyhanitabar and N. Karimian, "Kinetics of copper desorption of selected calcareous soils from Iran", IDOSI, Am-Euras. J. Agric. \& Environ. Sci., vol. 4, pp. 287-293, 2008.

[7] Y. S. Ho, J. C. Y. Ng and G. McKay, "Kinetics of pollutant sorption by biosorbents: review“, Taylor \& Francis, Sep. Purif. Methods, vol. 29, pp. 189-232, 2000.

[8] Z. Li, "Sorption kinetics of hexadecy ltrimethy lammonium on natural clinoptilolite", ACS, Langmuir, vol. 15, pp. 6438-6445, 1999.

[9] S.H. Chien and W.R. Clayton, "Application of elovich equation to the kinetics of phosphate release and sorption in soils", SSSA, Soil Sci. Soc. Am. J., vol. 44, pp. 265-268, 1980.

[10] H. Bashiri, "Desorption kinetics at the solid/solution interface: A theoretical description by statistical rate theory for close-to-equilibrium systems", ACS, J. Phys. Chem. C, vol. 115, pp. 5732-5739, 2011.

[11] W. Rudzinski, T. Borowiecki, T. Panczyk, A. Dominko and W. Gac, "Thermodesorption studies of energetic properties of nickel and nickel-molybdenum catalysts based on the statistical rate theory of interfacial transport", Elsevier, Applied Cataly sis A: General, vol. 224, pp. 299-310, 2002.

[12] T. Panczyk, W. Gac, M. Panczyk, T. Borowiecki and W. Rudzinski, "On the equilibrium nature of thermodesorption processes. TPD-NH $\mathrm{NH}_{3}$ studies of surface acidity of $\mathrm{Ni} / \mathrm{MgO}-\mathrm{Al}_{2} \mathrm{O}_{3}$ catalysts", ACS, Langmuir, vol. 22, pp. 6613-6621, 2006.

[13] S. Azizian and H. Bashiri, " Description of desorption kinetics at the solid/solution interface based on the statistical rate theory", ACS, Langmuir, vol. 24, pp. 13013-13018, 2008.

[14] C. A. Ward, "The rate of gas absorption at a liquid interface", AIP, J. Chem. Phys., vol. 67, pp. 229-235, 1977.

[15] C. A. Ward, R. D. Findlay and M. Rizk, "Statistical rate theory of interfacial transport. I. theoretical development", AIP, J. Chem. Phys., vol. 76, pp. 5599-5605, 1982.

[16] W. Rudzinski and T. Panczyk, " Kinetics of isothermal adsorption on energetically heterogeneous solid surfaces: a new theoretical description based on the statistical rate rheory of interfacial transport", ACS, J. Phys. Chem. B, vol. 104, pp. 9149-9162, 2000.

[17] T. Panczyk and W. Rudzinski, "A statistical rate theory approach to kinetics of dissociative gas adsorption on solids", ACS, J. Phys. Chem. B, vol. 108, pp. 2898-2909, 2004.

[18] W. Rudzinski and W. Plazinski, " Kinetics of solute adsorption at solid/solution interfaces: A theoretical development of the empirical pseudo-first and pseudo-second order kinetic rate equations, based on applying the statistical rate theory of interfacial transport", ACS, J. Phys. Chem. B, vol. 110, pp. 16514-16525, 2006.

[19] W. Rudzinski and W. Plazinski, "Application of the statistical rate theory of interfacial transport to investigate the kinetics of divalent metal ion adsorption onto the energetically heterogeneous surfaces of oxides and activated carbons", Elsevier, Appli. Surf. Sci., vol. 253, pp. 5814-5817, 2007.

[20] S. Azizian and H. Bashiri, "Adsorption kinetics at the solid/solution interface: statistical rate theory at initial times of adsorption and close to equilibrium", ACS, Lan gmuir, vol. 24, pp. 11669-11676, 2008.

[21] S. Azizian, H. Bashiri and H. Iloukhani, "Statistical rate theory approach to kinetics of competitive adsorption at the solid/solution interface", ACS, J. Phys. Chem. C, vol. 112, 
10251-10255, 2008.

[22] W. Rudzinski and W. Plazinski, "Theoretical description of the kinetics of solute adsorption at heterogeneous solid/solution interfaces, On the possibility of distinguishing between the diffusional and the surface reaction kinetics models", Elsevier, Appli. Surf. Sci., vol. 253, pp. 5827-5840, 2007.

[23] F. A. Houle and W. D. Hinsberg, "Stochastic simulations of temperature programmed desorption kinetics", Elsevier, Surf. Sci., vol. 338, pp. 329-346, 1995.
[24] F. A. Houle, W. D. Hinsberg and M. I. Sanches, "Kinetic model for positive tone resist dissolution and roughening", ACS, Macromolecules, vol. 35, pp. 8591-8600, 2002.

[25] B.S. Chu, B.S. Baharin, Y.B. Cheman and S.Y Queck, "Separation of vitamin E from palm fatty acid distillate using silica. III. Batch desorption study", Elsevier, J. Food Eng., vol. 64, pp. 1-7, 2004.

[26] M.X. Loukidou, T.D. Karapantsios, A.I. Zouboulis and K.A. Matis, "Diffusion kinetic study of cadmium(II) biosorption by Aeromonas caviae", SCI, J. Chem. Technol. Biotechnol., vol. 79, pp. 711-719, 2004. 